\title{
Increasing children's liking of vegetables through flavour-flavour learning
}

Citation for published version (APA):

Havermans, R. C., \& Jansen, A. T. M. (2007). Increasing children's liking of vegetables through flavourflavour learning. Appetite, 48(2), 259-262. https://doi.org/10.1016/j.appet.2006.08.063

Document status and date:

Published: 01/01/2007

DOI:

10.1016/j.appet.2006.08.063

Document Version:

Publisher's PDF, also known as Version of record

Document license:

Taverne

Please check the document version of this publication:

- A submitted manuscript is the version of the article upon submission and before peer-review. There can be important differences between the submitted version and the official published version of record.

People interested in the research are advised to contact the author for the final version of the publication, or visit the DOI to the publisher's website.

- The final author version and the galley proof are versions of the publication after peer review.

- The final published version features the final layout of the paper including the volume, issue and page numbers.

Link to publication

\footnotetext{
General rights rights.

- You may freely distribute the URL identifying the publication in the public portal. please follow below link for the End User Agreement:

www.umlib.nl/taverne-license

Take down policy

If you believe that this document breaches copyright please contact us at:

repository@maastrichtuniversity.nl

providing details and we will investigate your claim.
}

Copyright and moral rights for the publications made accessible in the public portal are retained by the authors and/or other copyright owners and it is a condition of accessing publications that users recognise and abide by the legal requirements associated with these

- Users may download and print one copy of any publication from the public portal for the purpose of private study or research.

- You may not further distribute the material or use it for any profit-making activity or commercial gain

If the publication is distributed under the terms of Article $25 \mathrm{fa}$ of the Dutch Copyright Act, indicated by the "Taverne" license above, 


\title{
Increasing children's liking of vegetables through flavour-flavour learning
}

\author{
Remco C. Havermans*, Anita Jansen \\ Maastricht University, Faculty of Psychology, Experimental Psychology, PO Box 616, 6200 MD Maastricht, The Netherlands
}

Received 8 June 2006; accepted 31 August 2006

\begin{abstract}
Positive flavour-flavour learning refers to a form of Pavlovian conditioning in which a neutral flavour is paired with an already preferred flavour. Due to this pairing one acquires an association between the neutral flavour and the liked flavour, resulting in a positive shift in liking and hence preference for the initially neutral flavour. In the present study, it was investigated whether a flavour-flavour learning procedure increases children's preference for a specific vegetable taste.Twenty one children were recruited and received six pairs of conditioning trials comprising the tasting of a sweetened vegetable and another unsweetened vegetable taste. At test the children had to evaluate the tastes unsweetened. Results show an increase in preference for the previously sweetened vegetable taste. It is concluded that flavour-flavour learning may be beneficial in increasing children's liking and acceptance of vegetables.
\end{abstract}

(C) 2006 Elsevier Ltd. All rights reserved.

Keywords: Children; Conditioning; Flavour preferences; Vegetables

The prevalence of childhood obesity is ever increasing. Although the health consequences of obesity are less severe at a younger age, childhood obesity tends to persist throughout adolescence and later adulthood. Moreover, obese adults are exposed to greater health risks when they have been obese since adolescence than obese persons having become obese during adulthood (Wadden, Brownell, \& Foster, 2002).

Obesity results from a disrupted energy balance, that is, more energy is consumed than expended. Therefore, increasing one's relative consumption of low-calorie dense foods such as fruits and vegetables should attenuate obesity and prevent the development of further overweight. Indeed, the consumption of fruit and vegetables has been found to be inversely related to body fatness (McCrory et al., 1999). Most people and especially children, though, do not consume much fruits and vegetables (Wardle et al., 2003). One reason for children's apparent reluctance to eat fruit and vegetables is that they simply do not like the taste

\footnotetext{
*Corresponding author. Tel.: + $31433884053 / \mathrm{E}$.

E-mail address: r.havermans@psychology.unimaas.nl (R.C. Havermans).
}

of it. Indeed, children particularly dislike the taste of vegetables (Gibson, Wardle, \& Watts, 1998). As there exists a high correlation between preferences and consumption, children's apparent reluctance to eat vegetables can largely be attributed to the experienced dislike of vegetables (see also Gibson et al., 1998). Increasing children's liking of vegetables should thus be considered beneficial in the sense that it increases acceptance of the taste of vegetables, and hence increases vegetable consumption making children less prone to develop overweight.

There are several potential methods to achieve a relevant shift in liking of vegetables. One method is mere exposure. Birch and colleagues have frequently demonstrated in children that repeated exposure to a specific taste will increase liking and acceptance of that taste (see Birch \& Fisher, 1996). More recently, Wardle et al. (2003) evaluated the efficacy of parent-led exposure in a randomized trial. They found that 10 consecutive days of exposure to a specific vegetable significantly increased children's acceptance of that taste and decreased their reluctance of trying other vegetables. Wardle and colleagues thus concluded that this method can be beneficial in promoting more healthy eating habits in children. 
Another potential method of increasing liking of vegetables is through flavour-nutrient learning. This is a form of Pavlovian conditioning in which an initially neutral flavour is consistently paired with a high caloric density (e.g., by adding macronutrients to the flavour). One learns to associate the flavour with the positive postingestive effects induced by its nutrient content and this will eventually lead to increased liking of the flavour. Such caloric conditioning of flavour preferences has repeatedly been demonstrated in children (Birch, McPhee, Steinberg, \& Sullivan, 1990; Jansen \& Tenney, 2001; Johnson, McPhee, \& Birch, 1991; Kern, McPhee, Fisher, Johnson, $\&$ Birch, 1993). One potential advantage of this method over mere exposure is that it requires very few learning trials to establish a relevant shift in preference (Capaldi, 1996). Although Gibson and Wardle (2003) showed in children that energy-density predicts the consumption of vegetables, it still needs to be established whether flavour-nutrient learning can be used to increase children's liking of the taste of vegetables. Further, although flavour-nutrient learning does not require many trials, it does generally require the ingestion of a substantial amount of food for one to be able to experience the postingestive consequences of the nutrients paired with it. Therefore, it may not be a very practical method to increase children's liking of vegetables, as children are likely hesitant to consume such amounts of vegetables in the first place. However, another flavour conditioning procedure, namely flavour-flavour learning, can be used which does not require substantial ingestion of vegetables. With this procedure, an initially neutral flavour is paired with an already highly preferred flavour (e.g., sweetness). One learns an association between the neutral flavour and the highly preferred flavour and this then leads to an increase in preference of the initially neutral flavour, even when subsequently presented unpaired. This effect has predominantly been investigated in animals, but there is some empirical evidence that flavour likes and dislikes in humans too can be conditioned through flavour-flavour learning, by pairing with already liked and disliked flavours, respectively (Baeyens, Crombez, Hendrickx, \& Eelen, 1995; Zellner, Rozin, Aron, \& Kulish, 1983). Zellner et al. (1983) demonstrated that students came to prefer a specific flavour of tea after it had been presented several times in combination with the sweet taste of sucrose. However, to our current knowledge it has not been tested whether a flavour-flavour learning procedure can similarly increase the liking of a specific vegetable taste in children. Therefore, in the present study, we investigated the efficacy of a flavour-flavour learning procedure to increase liking and preference for a given vegetable taste.

\section{Method}

The present study was approved by a local ethics committee. A total of 21 children (11 girls and 10 boys, $M$ age $=5.2$ years, $\mathrm{SD}=1.1)$ were recruited via primary schools. For each child, both parents provided informed consent before their child's participation in the experiment.

Children were tested in small groups $(n=2-5)$ during school hours. Two experimenters retrieved the children from their classroom and escorted them to a separate room in which they were seated behind any of the available school desks. There the children received six different vegetable flavours: zucchini, pumpkin, pea, cauliflower, broccoli, and carrot. These flavours had been prepared as follows. Fresh vegetables (i.e., zucchinis, pumpkins, peas, cauliflowers, broccoli, and carrots) were cooked separately until soft. The soft vegetables were then further mashed using a kitchen blender. Approximately $50 \mathrm{~g}$ of this mash was diluted in $100 \mathrm{ml}$ water and poured into a $250 \mathrm{ml}$ paper cup. The cup was sealed with an opaque plastic lid and a straw was inserted through the lid. At pre-test, the children received six identical cups each containing a distinct vegetable taste. This form of presentation was used, as we wanted to ascertain that any shift in flavour preference could only be ascribed to a shift in the evaluation of the taste and not some other sensory characteristic of the vegetable.

The children were instructed to take a sip of each cup and to categorize it as either liked, just okay, or disliked. Using these categories, the children were instructed to rank the tastes from one (most liked) to six (least liked) (see also Birch \& Sullivan, 1991). The tastes ranked three and four were then selected to serve as the conditioned stimuli (CS) during the subsequent conditioning phase. Children received three paired presentations of the two vegetable tastes they had ranked as three and four. These were prepared and served in a similar manner as the tastes during the pre-test. To one of these tastes, however, $\sim 20 \mathrm{~g}$ of dextrose per serving was added (CS+), whereas the other taste remained unsweetened (CS-). Whether the taste ranking three or four was sweetened with dextrose was determined randomly for each child. Carrot and cauliflower served seven times as one the two CSs, broccoli five times, pea four times, zucchini twice, and pumpkin served only once as a CS.

During conditioning, the children were instructed to sip and swallow from both drinks approximately every $5 \mathrm{~min}$. To keep the children engaged, the experimenter would also take a sip of a given vegetable taste with each pair of conditioning trials. The experimenter did not make any sounds, remarks or facial expressions reflecting (dis)approval of the taste as not to influence the children's evaluation of the tastes (see Baeyens, Vansteenwegen, De Houwer, \& Crombez, 1996). During conditioning, the children were allowed to make a drawing. After these first three conditioning trials, the children were escorted back to their classroom.

The following day, the same children were again retrieved from their classroom and escorted back to the separate room in which they received a further three pairs of conditioning trials. The reason for dividing the conditioning trials across 2 consecutive days was to limit 
potential strain on the children. Directly after the second conditioning session, the children received a post-test that was identical to the pre-test. Again, the six different vegetable-tastes were served (unsweetened) and children had to evaluate and rank these tastes. If flavour-flavour learning would be successful one would expect to see an increase in preference and liking of the taste previously sweetened (i.e. CS +) and no change in liking or preference for the taste not being paired with dextrose during conditioning (i.e. $\mathrm{CS}-$ ).

\section{Results and discussion}

A total of eight children refused to complete the experiment; that is, they did not wish to taste any more of the vegetable drinks after the pre-test. Therefore, the following analyses were conducted with the data of the 13 children (nine boys and four girls) who did complete the experiment.

At pre-test, 31 percent of the participants categorized CS- as liked and a similar percentage of participants categorized CS + as liked. However, at post-test, 15 percent of the participants categorized CS- as liked, whereas 54 percent categorized CS + as liked. This strongly implies an increase in preference for $\mathrm{CS}+$, but not for CS-.

To determine whether the taste being paired with dextrose had indeed increased in preference as opposed to the taste that was left unpaired during the conditioning trials, a repeated measures analysis of variance (ANOVA) was conducted with Test (pre-test vs. post-test) and CS (plus vs. minus) as the within-subject factors and ranking scores at pre-test and post-test as the dependent variable. Fig. 1 depicts the mean ranking scores of $\mathrm{CS}-$ and $\mathrm{CS}+$ before and after conditioning.

A marginally significant main effect of Test was found, $F(1,12)=4.39, p=.06$, indicating an overall positive shift in

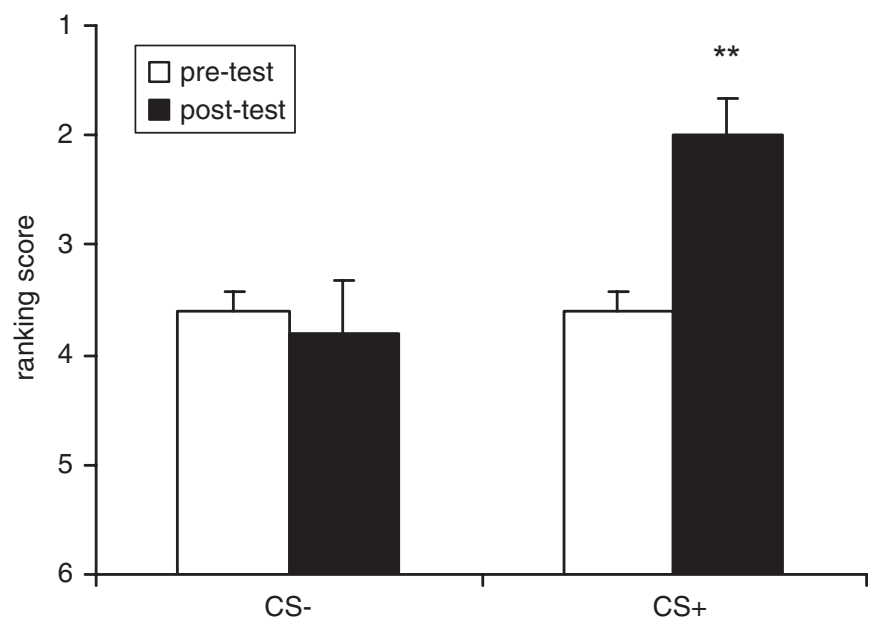

Fig. 1. The mean ranking scores $(+\mathrm{SEM})$ before and after conditioning for $\mathrm{CS}-$ and $\mathrm{CS}+.{ }^{* *}$ refers to $p<.01$ for the difference from pre-test rank. preference. Further, a main effect of CS was found, $F(1$, $12)=6.95, p<.05$, reflecting a preference for $\mathrm{CS}+$. More importantly though, a significant Test $\times$ CS interaction was found, $F(1,12)=5.83, p<.05$, implying that the positive shift in preference may have been limited to CS + . To further test this claim, we conducted post-hoc paired samples $t$-tests for each separate CS, comparing ranking of the given CS before and after conditioning trials. As predicted, CS + indeed demonstrated a significant increase in preference $\left(M_{\text {pre-conditioning }}=3.6 ; M_{\text {post-conditioning }}=2.0\right), t(12)=3.51$, $p<.01, d=1.71$, but no shift in preference was found for CS $-\left(M_{\text {pre-conditioning }}=3.6 ; \quad M_{\text {post-conditioning }}=3.8\right), t(12)=$ .56 , ns.

The results demonstrate that a flavour-flavour learning procedure effectively increases children's liking of a specific vegetable taste. A significant increase in flavour preference was found specifically for the vegetable taste being paired with the sweet taste of dextrose. The present pattern of results thus demonstrates that a positive shift in preference for the taste of a specific vegetable can be achieved within a short period of time.

One may wonder why no increase in liking was observed for the taste not being paired with dextrose. Although unpaired, children were repeatedly exposed to this taste and this mere exposure theoretically should have led to an increase in acceptance of that taste. The fact that it did not, however, can be ascribed to the small number of exposures. Birch, McPhee, Shoba, Pirok, and Steinberg (1987) demonstrated that young children require about 10-15 exposures to a given food to relevantly increase its acceptance. In that sense, one can argue that flavourflavour learning is a much more effective means to increase children's liking of vegetables. Furthermore, it has been found that conditioned flavour preferences are extremely resistant to extinction (see Baeyens, et al., 1995), suggesting that such conditioned taste preferences are stable over a longer period. Nonetheless, one might argue that -in contrast to repeated exposure to vegetable tastes - sweetening vegetables with sugar is at odds with the ultimate goal of reducing the propensity for obesity in children. This is a matter for debate. The present study shows that a clear shift in liking of unsweetened vegetable can be achieved after just six sips $(\sim 60 \mathrm{ml})$ of sugared vegetable.

It might be argued that the present pattern of results reflects flavour-nutrient learning, rather than flavour-flavour learning, as the CS + taste was paired with a nutrient reinforcer. Although the overall intake of dextrose was small, Ackroff and Sclafani (1994) demonstrated successful conditioning of flavour preferences when pairing a specific taste with the intragastric infusion of a very small amount of nutrient reinforcer (i.e., Polycose) in rats. In this study, however, differential conditioning trials $(\mathrm{CS}+/ \mathrm{CS}-)$ were conducted on alternate days, thus allowing for any postabsorptive effect of Polycose to be associated with the specific taste that was paired with its infusion. In the present experiment, the CS- and CS + trials were presented in pairs. Therefore, if one argues that the present 
findings can be ascribed to flavour-nutrient learning, then one would expect a similar increase in the liking of the CStaste as the postingestive consequence of dextrose would also have been contiguous with the presentation of this taste. Clearly, no such an effect was found. Participants demonstrated a positive shift in preference only for the $\mathrm{CS}+$ taste. Therefore, the present findings are best explained in terms of flavour-flavour learning. In line with this reasoning, a similar pattern of results is expected when using non-nutritive sweeteners such as saccharine, as has been shown in various animal studies (Capaldi, 1996). Theoretically, a similar pattern of results should also appear without actual ingestion of the sweetened flavour. Merely experiencing the taste of the sweetened vegetable should suffice in enhancing preference for that taste. In the present experiment, children were instructed to regularly sip and swallow the CS - tastes. In a future study, it could be examined whether a sip and spit procedure is equally effective at establishing an increase in liking and preference of a vegetable taste. This is particularly relevant as in the present study approximately a third of all the participants refused to complete the experiment. These children might have been less reluctant at completing the experiment if they had been allowed to sip and spit the tastes.

To recapitulate, the present results indicate that flavour-flavour learning appears to be efficacious in increasing liking of vegetables. However, the questions remain whether this positive shift in preference and liking is stable over a longer period of time, whether a similar shift can also be found when vegetables are served in a less unusual manner and whether the observed shift in preference indeed leads to a more healthy eating habit. These are all important questions that need to be addressed in future research to be able to fully assess the efficacy and health benefit of increasing children's liking of vegetables through flavour-flavour learning.

\section{Acknowledgements}

The authors would like to thank students Saskia Henschel, Salina Thijs, Bram Bronsveld, Miranda Beckers, Heleen Feenstra, Alice Wellum and Ellis Vossen for their aid in the recruitment and testing of the participants plus the many discussions on the topic.

\section{References}

Ackroff, K., \& Sclafani, A. (1994). Flavor preferences conditioned by intragastric infusions of dilute Polycose solutions. Physiology and Behavior, 55, 957-962.

Baeyens, F., Crombez, G., Hendrickx, H., \& Eelen, P. (1995). Parameters of human evaluative flavor-flavor conditioning. Learning and Motivation, 26, 141-160.

Baeyens, F., Vansteenwegen, D., De Houwer, J., \& Crombez, G. (1996) Observational conditioning of food valence in humans. Appetite, 27, 235-250.

Birch, L. L., \& Fisher, J. A. (1996). The role of experience in the development of children's eating behavior. In E. D. Capaldi (Ed.), Why we eat what we eat: The psychology of eating (pp. 113-141). Washington, DC: American Psychological Association.

Birch, L. L., McPhee, L., Shoba, B. C., Pirok, E., \& Steinberg, L. (1987). What kind of exposure reduces children's food neophobia? Looking vs. tasting. Appetite, 9, 171-178.

Birch, L. L., McPhee, L., Steinberg, L., \& Sullivan, S. (1990). Conditioned flavour preferences in young children. Physiology and Behavior, 47, 501-505.

Birch, L. L., \& Sullivan, S. (1991). Measuring children's food preferences. Journal of School Health, 61, 212-214.

Capaldi, E. D. (1996). Conditioned food preferences. In E. D. Capaldi (Ed.), Why we eat what we eat: The psychology of eating (pp. 53-80). Washington, DC: American Psychological Association.

Gibson, E. L., \& Wardle, J. (2003). Energy density predicts preferences for fruit and vegetables in 4-year-old children. Appetite, 41, 97-98.

Gibson, E. L., Wardle, J., \& Watts, C. J. (1998). Fruit and vegetable consumption, nutritional knowledge and beliefs in mothers and children. Appetite, 31, 205-228.

Jansen, A., \& Tenney, N. (2001). Seeing mum drinking a 'light' product: Is social learning a stronger determinant of taste preference acquisition than caloric conditioning? European Journal of Clinical Nutrition, 55 , $418-422$.

Johnson, S., McPhee, L., \& Birch, L. L. (1991). Conditioned preferences: Young children prefer flavors associated with high dietary fat. Physiology and Behavior, 50, 1245-1251.

Kern, D. L., McPhee, L., Fisher, J., Johnson, S., \& Birch, L. L. (1993). The postingestive consequences of fat condition preferences for flavors associated with high dietary fat. Physiology and Behavior, 54, 71-76.

McCrory, M. A., Fuss, P. J., McCallum, J. E., Yao, M., Vinken, A. G., Hays, N. P., et al. (1999). Dietary variety within food groups: Association with energy intake and body fatness in men and women. American Journal of Clinical Nutrition, 69, 440-447.

Wadden, T. A., Brownell, K. D., \& Foster, G. D. (2002). Obesity: Responding to the global epidemic. Journal of Consulting and Clinical Psychology, 70, 510-525.

Wardle, J., Cooke, L. J., Gibson, E. L., Sapochnik, M., Sheiham, A., \& Lawson, M. (2003). Increasing children's acceptance of vegetables; a randomized trial of parent-led exposure. Appetite, 40, 155-162.

Zellner, D. A., Rozin, P., Aron, M., \& Kulish, C. (1983). Conditioned enhancement of human's liking for flavors associated with sweetness. Learning and Motivation, 14, 338-350. 